\title{
An example of text analysis software (EMOTAIX- Tropes) use: The influence of anxiety on expressive writing
}

Annie PIOLAT and Rachid BANNOUR

\section{(2) OpenEdition \\ Journals}

Electronic version

URL: http://journals.openedition.org/cpl/4879

DOI: $10.4000 / \mathrm{cpl} .4879$

ISSN: $1379-6100$

Publisher

Centre PsyCLÉ

\section{Electronic reference}

Annie PIOLAT and Rachid BANNOUR, «An example of text analysis software (EMOTAIX-Tropes) use: The influence of anxiety on expressive writing », Current psychology letters [Online], Vol. 25, Issue 2, 2009 | 2009, Online since 06 April 2009, connection on 07 September 2020. URL : http:// journals.openedition.org/cpl/4879; DOI : https://doi.org/10.4000/cpl.4879

This text was automatically generated on 7 September 2020

(C) All rights reserved 


\title{
An example of text analysis software (EMOTAIX-Tropes) use: The influence of anxiety on expressive writing
}

\author{
Annie PIOLAT and Rachid BANNOUR
}

\section{Introduction}

1 The main purpose of this article is to introduce English-speaking readers to a tool for analyzing the French emotional and affective lexicon (EMOTAIX-Tropes). In the first section, we explain how the lexical items were collated, classified and organized. In order to demonstrate how this text analysis tool can be used by researchers, we then go on to describe a novel experiment designed to investigate the effect of students' anxiety on the way in which they described their feelings after passing or failing an exam.

We first realized that there was a need for a tool like ours after discovering the valuable research undertaken by Pennebaker, Francis and Booth (2001), who had developed a tool for automatically detecting and counting words in texts (LIWC: Linguistic Inquiry and Word Count; for the latest version, see Pennebaker, Chung, Ireland, Gonzales, \& Booth, 2007). It was obviously vital to have a similar tool which would allow us to automatically identify French lexical items referring to emotions, moods, affects and feelings. The tool we have developed will promote the study of both the spoken and written expression of emotions in several different areas of psychology, including work, health and education. EMOTAIX-Tropes will provide users with classified and quantified data for every corpus they analyze. These data will serve a variety of purposes, such as diagnosing the emotional state of people who have described their feelings in an interview or in a private diary, and comparing the emotional states of groups of people belonging to different sociocultural strata who 
have been asked to express themselves verbally in particular contexts, as in Pennebaker, Mehl and Niederhoffer's study (2003). Our contribution has been to build and organize the EMOTAIX scenario embedded in the Tropes software. The latter features a series of text analysis functionalities, some of which can be likened to those provided by LIWC.

\section{Part 1. Emotaix: a tool for detecting and quantifying the emotional and affective lexicon}

3 In this section, we describe the EMOTAIX (EMOTion and AIX-en-provence) scenario. The justifications for our theoretical decisions and our modus operandi are explained considerable detail in an article written in French (Piolat \& Bannour, in press). Our objective here is simply to provide enough information for an English-speaking reader to understand what EMOTAIX is and how it works when it is used to detect and quantify different categories of the emotional lexicon.

\section{Choice of the Tropes discourse analysis software}

4 Rather than attempt to translate LIWC, as has been done for Spanish (Ramirez-Esparza, Pennebaker, Garcia, \& Suria, 2007) and German (Wolf, Horn, Mehl, Pennebaker \& Kordy, 2008), we preferred to use an existing high-performance French-language discourse analysis program. The advantages of Tropes include its ability to carry out stylistic, syntactic and semantic analyses and to present the results in graph and table form (for a description in English, see the following Website: http://www.semanticknowledge.com/doc/V70/text-analysis.html). When conducting research comparable to that carried out by Pennebaker and his team, it is important to note that Tropes can yield information about a text that is different from yet similar to that provided by LIWC2007, such as stylistic/rhetorical analyses (argumentative, enunciative, descriptive or narrative style). It can also identify different word categories (verbs, connectors, personal pronouns, modalities, qualifying adjectives), conduct thematic analyses (reference fields), and detect discursive/chronological structures.

5 In order to highlight the different themes touched on in a document, Tropes can draw on 20,000 equivalent classes divided into broad semantic categories. An equivalent class is presented as a "concept" or "theme", grouping together synonyms or closely-related terms (substantives only). Content can be analyzed at three hierarchical levels. The most fine-grained analysis identifies the "references" of the words used in the text. These references are grouped together into the reference fields 2 which, in turn, are merged into the broader reference fields 1 , corresponding to the most coarse-grained level of analysis. Focusing on the analysis of emotional and affective lexicon, we tested Tropes' ability to detect and classify lexical items pertaining to emotions, feelings, moods and affects contained in a variety of corpora. There are several problems with this type of analysis: a) emotional lexical units are distributed across a large number of references, some of which concern neither emotion nor affect; b) these units are classified according to their literal meaning, without taking their possible figurative use into account (e.g. abattement [lit. (tax) allowance; fig. despondency] is classified under "business" and is therefore not recorded as a synonym of weariness, despondency, 
etc.); c) the references are not organized around a hedonic axis (Pleasant vs. Unpleasant), which we regard as a vital structural criterion.

6 Crucially, Tropes allows users to create a personalized scenario alongside its generalpurpose one. The former can be organized to meet one's own specifications and the two then used together. We therefore decided to construct the EMOTAIX scenario. While LIWC2007 contains approximately one thousand words or word-stems (references) belonging to the emotional lexicon, the number of emotional and affective items included in the current version of EMOTAIX described below, is far greater: 2,014 references (cf. Table 1). Furthermore, these emotion-related terms are thematically organized in a more highly-specified way than they are in LIWC; their valence is preserved and figurative meanings are ascribed to them as and when required.

\section{Procedure for building the emotional and affective lexicon}

7 EMOTAIX (Version V1_2) is made up of 2,014 references. The term "reference" (generally a substantive) designates one or more words sharing the same stem and having similar meanings. Words classified under a particular reference may occur in several different grammatical categories (verb, adjective, and adverb). If no appropriate noun is available, the reference takes the form of a verb, and in the absence of the latter, an adjective. In some cases, a reference may correspond to a figure of speech (fixed syntagm), such as "sang d'encre" [very worried].

8 Emotional and affective items were initially collected from a variety of sources. Some of these supplied straightforward lists of terms (most originally in English and subsequently translated into French), others gave information about valence and intensity, while others again suggested ways of organizing these terms, based on either a model or experimental findings. These sources included Cowie and Cornelius (2003), Frijda, Markam, Sato and Wiers (1995), Galati and Sini (1998), Niedenthal et al. (2004), Ortony and Turner (1990), Pennebaker et al. (2001), Plutchik (2005), Feldman Barrett and Russell (1999), Scherer (2005), Shaver, Schwartz, Kirson and O'Connor (1987, and Storm and Storm (1987) (for an exhaustive list, see Piolat and Bannour (2009)). Terms were also gleaned from questionnaires designed to assess subjects' current emotional state (PANAS, Watson, Clark \& Tellegen, 1988), affect intensity (AIM, Larsen \& Diener, 1984), emotional expressivity (EES, Kring, Smith \& Neale, 1994) and appraisal processes (GAQ, Scherer, 2001), as well as certain types of apprehension (WAT, Daly \& Miller, 1975; PRCA, McCroskey, Beatty, Kearney \& Plax, 1985) or anxiety (STAI, Spielberger, Gorsuch, Lushene, Vaag, \& Jacobs, 1983) and mental rumination (TCQ, Wells \& Davies, 1994). Questionnaires used to assess the level of alexithymia also served as sources (TAS-20, Loas, Otmani, Verrier, Fremaux, \& Marchand, 1996; BVAQ, Bermond, Vorst, Vingerhoets, \& Gerritsen, 1999).

9 In order to decide whether or not to include a particular term in EMOTAIX, we made use of the online "lexical portal" of the National Centre for Textual and Lexical Resources [CNRTL: http://www.cnrtl.fr/], which supplies definitions from several dictionaries, including Le Trésor de la Langue Française informatisé (TLFi). This also proved to be a means of gathering yet more terms. We always took the content of the CNRTL definition into account, whatever the term's grammatical category (noun, verb, adverb, adjective). For a term to be included in our collection, its definition (literal or figurative meaning) had to include at least one of the following semantic characteristics: affection, 
character, emotion, affective state, emotional state, psychological state, moral strength/ weakness, mood, feeling, temperament, personality trait or affective disorder. We decided that terms could also be included in the collection if their definitions contained words relating either to the "classic" emotional lexicon (anger, gaiety, sadness, disgust, etc.) or to pleasant or unpleasant psychological states (depression, discouragement, euphoria, relief, etc.). We also exploited the "Synonyms" and "Antonyms" entries of the CNRTL for the terms being assessed. This step-by-step approach, tracking down synonyms and antonyms, yielded a huge sample of terms, some of which were never (or only rarely) included in the articles cited above as sources. These were words concerning a) the physical manifestations of emotional or affective states (to be livid, to have gooseflesh, etc.), b) personality traits (irascible, helpful, cowardly,etc.), c) mental illness (madness, paranoia, autism, etc.) and d) certain symptoms (addiction, anorexia, mania, etc.). It was particularly important to include these terms, as speakers/writers freely use them when describing their own experiences: "It was sheer madness in the run-up to those exams, I was in a state of total paranoia; "When the exams come, I forget all about being helpful and I'm constantly irascible".

10 As we went along, we came across new terms (or expressions) whose meanings only referred to an emotion or affect if they were used figuratively (figurative meaning: second meaning generated by a figure of speech, especially a metaphor, e.g. "to be hotheaded = to be irascible"). We soon found ourselves with a great many of these figurative terms (58.09\% of references; cf. Table 1 for a detailed breakdown). When including them in the collection, it was vital to flag their "figurative" nature. This is because EMOTAIX users analyzing a corpus had to be able to check whether the term had been used in its figurative meaning, in order to convey an emotion (thereby allowing them to count it as such) or in its literal one (implying that it should not be counted), e.g. déboussoler (disorient) vs. déboussoler (confuse); éblouissement (dazzle [eyesight problem]) vs. éblouissement (dazzle [admiration]). It is extremely difficult to establish a comprehensive collection of terms which refer figuratively to an emotion, as speakers/ writers freely transpose words in order to manipulate their meanings. For example, some students seeking to express the fact that they were extremely despondent when they learned that they had failed an exam used the following expressions: "I was destroyed... demolished... exploded" and even "I was dynamited... guillotined... executed". In order to delimit our collection of figurative terms, we therefore turned, once more, to the CNRTL. Our decisions to reject certain terms were based on various observations. For example, "dynamited" was not kept, as it is not one of the synonyms most frequently given for the term "exploded". Furthermore, its infinitive form does not have any synonym (or antonym) which would justify its inclusion in an emotionrelated equivalent class. It should be noted that, by introducing figurative terms and expressions into our collection, we accepted items described as familiar, slang or popular, such as pétoche for peur [apprehension] and broyer du noir for tristesse [sadness].These types of terms are not mentioned in the articles on emotional and affective psychology that we took as our sources, although Scherer (2005) did add a number of so-called "popular" terms to his collection of 280 terms. Just as Pennebaker and his team $(2001,2007)$ inserted a couple of swear words into their LIWC software so we, too, selected exclamations (e.g., Sapristi [Heavens]) and swear words (e.g., Nom de Dieu [Christ almighty]), when these conveyed an emotion of surprise, irritation, etc. Our aim in encompassing these lexical registers was to allow the analysis of different types 
of oral and written documents tackling a wide variety of themes and produced in highly diversified communication contexts.

11 To conclude, we freely acknowledge our failure to capture every single metaphorical use of terms expressing emotional feelings. However, in order to make our tool manageable, we decided to call a halt to our collecting at some point, and this we did in February 2008. The frontiers of the collection can, in any case, easily be reopened in order to admit terms whose absence would hinder the analysis of corpora gathered in specific contexts. The collection currently contains 2,014 references grouping together 4,921 words (verbs, adverbs, adjectives). The terms are listed in one huge Excel table available at the following address: http://sites.univ-provence.fr/wpsycle/ EMOTAIX_FREE/emotaix.htm.

\section{Organization of EMOTAIX based on valence and other aspects}

12 The structure of our collection of references is intended to ensure that the application of the EMOTAIX scenario to different corpora is not restricted to the automatic detection and counting of the emotional items they contain (cf. Table 1). The scenario is intended not only to count these lexical items but also to classify them according to three different aspects: (1) valence (positive/negative), (2) use (literal/figurative meaning) and (3) nature (semantic category; cf. Table 2).

13 The classification of the emotional items according to their positive or negative valence proved to be both quick and easy, thank to the CNRTL definitions, which contain words denoting aspects that are either pleasant, attractive, desirable, satisfying, etc. or unpleasant, repulsive, undesirable, dissatisfying, etc. 
Table I. Distribution of the 2,014 references and 4,921 words within the EMOTAIX scenario according to their valence (positive vs. negative) and use (literal vs. figurative meaning). (NB. The UNSPECIFIED EMOTIONS, SURPRISE and IMPASSIVENESS categories have no a priori valence).

\begin{tabular}{llll}
\hline References & Literal meanings & $\begin{array}{l}\text { Figurative } \\
\text { meanings }\end{array}$ & Total \\
\hline Positive & $294(54.95 \%)$ & $241(45.05 \%)$ & $535(26.56 \%)$ \\
Negative & $472(37.73 \%)$ & $779(62.27 \%)$ & $1,251(62.12 \%)$ \\
Unspecified & $53(36.81 \%)$ & $91(63.19 \%)$ & $144(7.15 \%)$ \\
Surprise & $14(25.45 \%)$ & $41(74.55 \%)$ & $55(2.73 \%)$ \\
Impussiveness & $11(37.93 \%)$ & $18(62.07 \%)$ & $29(1.44 \%)$ \\
\hline Total & $844(41.91 \%)$ & $1,170(58,09 \%)$ & $2,014(100 \%)$ \\
\hline Terms included & Literal meanings & Figurative & Total \\
in the references & & meanings & \\
\hline Positive & $798(61.01 \%)$ & $510(38.99 \%)$ & $1,308(26.58 \%)$ \\
\hline Negative & $1,294(42.04 \%)$ & $1,784(57.96 \%)$ & $3,078(62.55 \%)$ \\
\hline Unspecified & $142(42.26 \%)$ & $194(57.74 \%)$ & $336(6.83 \%)$ \\
\hline Surprise & $42(29.17 \%)$ & $102(70.83 \%)$ & $144(2.93 \%)$ \\
\hline Impassiveness & $23(41.82 \%)$ & $32(58.18 \%)$ & $55(1.12 \%)$ \\
\hline Total & $2,299(46.72 \%)$ & $2,622(53.28 \%)$ & $4,921(100 \%)$ \\
\hline
\end{tabular}

14 Although we encountered three problems, we were able to overcome them by extending the initial organization of the scenario, as shown in Table 1. First of all, the CNRTL definitions of terms such as emotion, feeling and mood gave no clues as to their valence. These terms have bivalent meanings, as illustrated by the definition of the term emotion: "Reactive, reflexive, involuntary behavior, experienced simultaneously at the bodily level, in a more or less violent manner, and affectively, in the pleasure or pain mode". We therefore created a specific category for them, entitled "UNSPECIFIED EMOTIONS". This means that when the scenario is applied to a corpus in which the speaker/writer has used them, they are identified by the software as being "unspecified". The user then knows that the valence of these terms has to be determined in the light of the context in which the speaker/writer has expressed them. Depending on this context, the valence can normally then be described as either positive or negative. There are, however, instances where the speaker/writer states that he or she has experienced an emotion, but fails to add the content which would allow us to infer whether he or she found this emotion pleasant or unpleasant. In these circumstances, the term has to remain "unspecified". The second problem was that with the CNRTL, it is impossible to attribute a positive or negative valence to emotions concerning surprise and its synonyms (astonishment, amazement, etc. (for a discussion of this problem, see Fontaine, Scherer, Roesch \& Ellsworth, 2007, who emphasize the specific features of this emotion). We therefore gave them a category of their own, so that EMOTAIX users would be free to decide on their positive or negative valence according to their specific verbal environment. This is generally easy to do, for although the speaker/writer may in theory fail to provide enough information to decide on the pleasant or unpleasant aspect of the surprise, this only rarely happens in 
practice. Thirdly and lastly, the sources we used to establish our collection did not all list terms allowing speakers/writers to express an absence of emotion, feeling or affect. Without going so far as to claim that these terms are actually alexithymic in nature (Sifneos, 1988), we did find several terms in our everyday language which allow us to express this state, such as fearlessness, imperturbability, stony-faced, etc. Accordingly, as shown in Table 1, we established a third valence-free category, entitled IMPASSIVENESS. The terms placed in this category are not to be confused with those conveying low-intensity sensations, such as "Weariness" and "Torpor", whose valence is indicated by the CNRTL.

15 To conclude this description, we should stress that our initial mode of classification prevented us from indicating the degree of intensity (high/low) of these terms. Intensity refers to the idea that an emotion can be felt more or less strongly, and that this strength or weakness can be described and subjectively rated. Based on judgments provided by a huge sample of participants, Niedenthal et al. (1994) calculated the intensity of 237 terms. However, as our own collection of terms continued to "grow like Topsy", it became very time consuming to ask judges to assess their intensity on a Likert scale, as we had initially done (Bannour, Piolat \& Gombert, 2008). Scherer (2005) also reported the difficulty of using informants' judgments to establish the level of intensity of the terms he collected.

16 Interestingly, at this point in the construction of the scenario, negative-valence terms accounted for $62.12 \%(\mathrm{~N}=1251)$ of the collection, while positive-valence ones represented just $26.56 \%(\mathrm{~N}=535)$. Although we did attempt to redress the balance by searching for other positive-valence terms in the CNRTL, this tactic proved ineffectual. It would appear that speakers/writers quite simply have a greater choice of terms available to them to express their negative emotional states than they do to express their positive ones. This imbalance in lexical resources had already been highlighted in previous studies on both the French lexicon (Galati \& Sini, 1998; Niedenthal et al., 2004) and the English one (Averill, 1980).

\section{Organization of EMOTAIX into content categories}

17 The purpose of this second stage was to allow EMOTAIX users to identify the emotional contents expressed in a corpus by assigning all the terms that have been isolated to semantic categories. As we have explained in a previous article (Piolat \& Bannour, 2009), we were unable to apply existing methods of structuring models of emotion and/ or affect, such as those developed by Plutchik (2005), Russell and Feldman Barrett (1999), or even Scherer (2005), as the categories established by these authors were not suitable for all the terms in our collection.

18 Using the CNRTL, and a process of semantic rapprochement, mainly achieved through trial and error, we eventually came up with nearly 70 basic categories. We then organized these categories on either side of a hedonic axis, taking account of the positive or negative valence of the references (excluding the UNSPECIFIED EMOTIONS, SURPRISE and IMPASSIVENESS categories). We then set ourselves the rule that the basic categories would have to be strict opposites (e.g. "Disgust" vs. "Desire"; "Concern" vs. "Relaxation"). This was a vital condition, as EMOTAIX users analyzing a text must bear in mind that the speaker/writer can syntactically negate the content of any term (e.g. I love opera vs. I don't like opera; I'm disgusted with my exam results vs. I'm not 
too disgusted with my exam results). Whenever a term belonging to the emotional lexicon is negated within a text, the user must be able to classify it in its opposing category. As we went along, we realized that some of the 70 basic categories constructed from synonyms had no clear-cut opposing category, as the corresponding antonyms could be placed in two or more opposing categories. Through a process of trial and error, we arrived at a total of 28 basic categories on each side of the hedonic axis. The CNRTL played a key role in tracking down the synonyms and antonyms. It also proved useful in checking the semantic negation. For example, a satisfactory correspondence was found to exist between the terms in the "Love" basic category and those included in the opposing "Resentment" one (antonyms).

19 At this point in the proceedings, we decided that this positive/negative-valence structure would not suffice, as we believed that EMOTAIX users should not have to confine themselves to the molecular level of text analysis imposed by the basic categories. They should also be able to describe the content at a more molar level, especially if they are using EMOTAIX to analyze and compare the contents of a large number of texts. We therefore opted for three hierarchical levels of organization, nesting each content category into the one above. The decision to adopt this "Russian doll" model was taken in order to preserve the idea that affects form a structural backdrop for feelings which, in turn can be divided into more specific feelings or emotions (cf. Feldman Barrett \& Russell, 1999; Plutchik, 2003; Scherer, 2005). We checked the validity of our classification by making sure that the upper categories fulfilled a twofold function: (1) providing as good a fit as possible for some if not all of the meaning of the words belonging to their basic categories, and (2) maintaining an antinomic relationship with some if not all of the meaning of the categories at the same hierarchical level, as well as of the basic categories they encompassed. Furthermore, wherever possible, the labels of the superordinate (in capitals) and supraordinate (bold capitals) categories were chosen for their "literal" meaning. These labels corresponded to references included in one of the basic categories they designated. We deliberately chose not to use the same name for both nested and nesting categories. Thus, as the term "HATE" was being used to designate a supercategory, it could be chosen as the heading for one of the four basic categories which contained synonyms closely related to this term. For this reason, the basic category in question was labeled "Resentment". In this way, we eventually arrived at the form of content organization set out in Table 2. 
Table 2. EMOTAIX comprises $2 \times 28$ basic categories (center) organized into three hierarchical levels on either side of a hedonic axis (positive and negative valence), with which 3 valence-free categories are associated (SURPRISE, UNSPECIFIED EMOTIONS, IMPASSIVENESS). The numbers of references are shown next to the category headings.

\begin{tabular}{|c|c|c|c|c|c|}
\hline \multirow{8}{*}{ 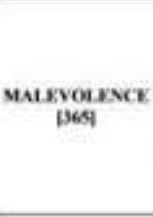 } & \multirow{4}{*}{$\begin{array}{l}\text { Hant } \\
\text { [227] }\end{array}$} & Ronermentsigi & Lore[5s] & \multirow{4}{*}{$\begin{array}{c}\text { AmbenoN } \\
{[128]}\end{array}$} & \multirow{8}{*}{$\begin{array}{l}\text { BENEVOL:ESC } \\
1109\end{array}$} \\
\hline & & Dhyua ISII & Deirz134] & & \\
\hline & & Didain [45] & Abrintion [18] & & \\
\hline & & Imituan $[\mathrm{BP}]$ & Annodina [3] & & \\
\hline & \multirow{4}{*}{$\begin{array}{l}\text { ACKESSSIVENESS } \\
\text { [138] }\end{array}$} & Intumaity [16] & Conchecula3] & \multirow{4}{*}{ KINDNESS [SS] } & \\
\hline & & Rage [4II & Centiknes [17] & & \\
\hline & & Anger [59] & Patiensa [2] & & \\
\hline & & Mise $[26]$ & Hemily [3] & & \\
\hline \multirow{14}{*}{ 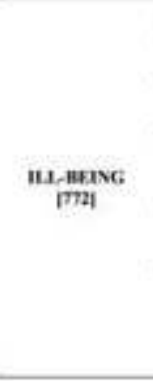 } & \multirow{3}{*}{ 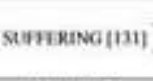 } & Tandy [12] & Hัพ 17 & \multirow{3}{*}{$\begin{array}{l}\text { HAPPINSSS } \\
\text { [Si] }\end{array}$} & \multirow{14}{*}{$\begin{array}{c}\text { WKLL-BFINC } \\
\text { [279] }\end{array}$} \\
\hline & & Fein [111] & loy [2I] & & \\
\hline & & Tez $|7|$ & Lest 123 & & \\
\hline & \multirow{2}{*}{$\begin{array}{c}\text { MaDNESS } \\
|76|\end{array}$} & Meneal ithori 36 ] & Menal hatele flof & \multirow{2}{*}{$\begin{array}{c}\text { Uxcmirr } \\
\text { [1T] }\end{array}$} & \\
\hline & & Ronding $[40]$ & Cominen vore [J] & & \\
\hline & \multirow{3}{*}{ 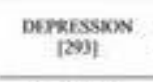 } & Sadhes $[0\}]$ & Caskty [20] & \multirow{3}{*}{$\begin{array}{l}\text { SPixeT } \\
\text { [9]| }\end{array}$} & \\
\hline & & Wearines $(179)$ & Virestay iogl & & \\
\hline & & $\operatorname{Tapox}[56]$ & Anesal 19 & & \\
\hline & \multirow{2}{*}{$\begin{array}{l}\text { DisokDES } \\
\text { [142] }\end{array}$} & Trable [1119] & Arsusemara 137 & \multirow{2}{*}{$\begin{array}{l}\text { Reuef } \\
\text { |99] }\end{array}$} & \\
\hline & & Rewne $[23]$ & Redacas $\mid 22]$ & & \\
\hline & \multirow{4}{*}{$\begin{array}{l}\text { ERUSTRATION } \\
\text { [130] }\end{array}$} & Ituminesen $[57]$ & Fiemen $[10]$ & \multirow{4}{*}{$\begin{array}{l}\text { SATISFACTION } \\
\text { [61] }\end{array}$} & \\
\hline & & Dicuatiataxtion [17] & Fulfiliman [1]" & & \\
\hline & & Dipleswere $[40]$ & Nonure [26] & & \\
\hline & & Fogresion $[16]$ & Caturisi[1]] & & \\
\hline \multirow{6}{*}{$\underset{|114|}{\operatorname{AxxiETy}}$} & \multirow{3}{*}{$\underset{|61|}{\text { neNk }}$} & Tame [10] & Bolthera 1 16] & \multirow{3}{*}{$\begin{array}{c}\text { couraca } \\
\text { [3i] }\end{array}$} & \multirow{6}{*}{$\begin{array}{c}\text { Controsa ue } \\
\mid \text { Ty| }\end{array}$} \\
\hline & & Apenthemion [37] & Selfomnfidmat [19] & & \\
\hline & & Shyomat $[14]$ & $\ln 19$ & & \\
\hline & \multirow{3}{*}{$\begin{array}{c}\text { monsion } \\
\text { [5]| }\end{array}$} & Panis $\{4]$ & Setrenity [14] & \multirow{3}{*}{$\begin{array}{c}\text { CALM } \\
\text { (42) }\end{array}$} & \\
\hline & & Dineros [18] & Trempuilivy [16] & & \\
\hline & & Cosenen $[31]$ & Returation 1121 & & \\
\hline \multicolumn{2}{|c|}{ SERPRESE [SS] } & UXSFECIVED R & Hornovs $|14|$ & \multicolumn{2}{|c|}{ MURASSIVENESS |29| } \\
\hline
\end{tabular}

20 It should be noted that the MADNESS and LUCIDITY supercategories and the basic categories they encompass (Mental illness, Rambling vs. Sanity, Common sense) proved particularly difficult to construct. The reasons were twofold. For a start, these terms (plus a great many of their synonyms) rarely, if ever, appear in the lists of emotional and affective items given in the articles we used as our sources. This is despite the fact that the CNRTL definitions of MADNESS and most of its synonyms (Distraction, Rambling, Crazy, etc.) that prompted us to add these terms to our collection in the first place include comments such as "strong emotion" and "violent feeling". Due to the presence of the hedonic axis and the attendant need to place a positive-valence supercategory opposite the MADNESS negative-valence supercategory, we deemed it necessary to create a LUCIDITY supercategory containing antinomic terms. We were, however, only able to find a few references (Equilibrium, Reason, Perceptiveness, etc.), as most of the synonyms, such as reasoning, intelligence and mind, refer to intellectual function - a function which falls outside the ambit of affect or emotion, according to the CNRTL. As a result, they had to be excluded. Within these two supercategories, we established the "Mental illness" vs. "Mental health" basic categories. We chose these labels by default, insofar as they were the least bad labels for the references they encompassed, while at the same time fitting into the ILL-BEING vs. WELL-BEING supracategories.

21 Lastly, it should be noted that the numbers of references in each EMOTAIX basic category varied widely (e.g. 9 in Arousal, 2 in Patience, 7 in Tear, 4 in Panic). In the face of these disparities, we resumed our searching in an attempt to increase the numbers of references in the least represented categories, but in vain. Accordingly, some categories contain relatively few semantic equivalents, especially the positive-valence basic categories. 


\section{EMOTAIX operating instructions}

22 downloaded from the following address: http://sites.univ-provence.fr/wpsycle/ EMOTAIX_FREE/emotaix.htm. A zipped archive entitled "EMOTAIX_free" contains (1) the "EMOTAIX_2008_V1_2.scn" scenario, (2) a set of instructions, (3) a score sheet and (4) an Excel table showing how the 2,014 references and their associated terms are organized. To implement the text analysis system, the user can download the demonstration version of Tropes, available from the Semantic-Knowledge Website. The downloadable operating instructions explain how to incorporate the EMOTAIX_2008_V1_2.scn scenario into this demonstration version. The user can then analyze a corpus using the Tropes functionalities and the EMOTAIX scenario, in order to detect and automatically count the emotional and affective items.

Although the downloadable instructions include technical advice on how to use EMOTAIX to identify and count emotional and affective items; it is vital to check each word identification and, therefore, each wordcount performed by EMOTAIX, viewing each term it identifies on the screen in its verbal environment. Given the potentially metaphorical use of $58.09 \%$ of the EMOTAIX terms and the speaker/writer's own syntactic flexibility, which means that the valence of a term can be inverted by using a simple negation, each term detected by EMOTAIX must be examined and will, in some cases, have to be rejected (non-emotional literal meaning) or clarified (unspecified emotions or surprise) and/or reassigned (negative syntax).

24

Once the corpus analysis is complete, the EMOTAIX user can exploit the emotional lexicon occurrences and construct various dependent variables, according to his or her research goals. The study described below, in which we explored the relationship between students' anxiety levels and the way in which they expressed their feelings after passing or failing an exam, demonstrates the usefulness of this tool. The results concern indicators such as the emotional load of the written texts (e.g. ratios between (a) the number of emotional terms and the total wordcount, (b) positive- and negativevalence terms, (c) "literal" and "figurative" terms, etc.). Other indicators reflect emotional and affective contents, based on (d) an analysis of the number of students who evoked a particular category through the inclusion of one or more relevant terms in their texts. Lastly, we sought to ascertain whether the number of emotional terms in a given category could be explained by the students' level of anxiety.

\section{Part 2. Experimental Illustration}

\section{Objectives}

Exams are one of the major challenges facing populations of young adults, as their future career depends to a considerable extent on their success or failure. Exams can therefore be perceived of as unavoidable threats. According to Spielberger (1972), anxiety can be defined as an individual's response to environmental demands. State anxiety is thought to derive from the perception of threat, whereas trait anxiety is an enduring characteristic of the personality, defined as a predisposition to perceive some situations as more or less worrying and to respond with heightened states of anxiety. High trait anxious people are more prone to perceiving situations as threatening and to

Current psychology letters, Vol. 25, Issue 2, 2009| 2009 
responding with heightened states of anxiety. They develop more negative affects, as well as feelings of tension and apprehension, and tend to ascribe their successes and failures to external causes beyond their control. Less anxious people, on the other hand, tend to take responsibility for events. People with high trait anxiety also tend to have low self-esteem and a lack of confidence in their own resources.

Following on from the study by Pennebaker, Mehl and Niederhoffer (2003), we sought to demonstrate that students express their emotional experiences in different ways, according to the level of their trait anxiety. Participants were asked to recall an occasion when they passed or failed an exam that was important to them, describing their feelings. We hypothesized that although the act of constructing a story would prompt them to adopt a relatively similar narrative structure (Goldman, Graesser \& Broek Van Den, 1999), the level of their trait anxiety would nonetheless be reflected in the way they described their well-being or ill-being during this anxiogenic event, marking the culmination of a period of training or study.

\section{Method}

\section{Material}

\section{Expressive writing topics}

27 Passing or failing an exam is a reality experienced by all students, who are continually striving to obtain qualifications. This has made it a popular topic for expressive writing (Smyth \& Pennebaker, 2008), especially as two versions are available - one encouraging the expression of positive emotions (success), the other the expression of negative ones (failure). The instructions for these two versions were as follows:

Write a text expressing what you felt after failing an exam (baccalaureate, driving test or any other exam that was important to you). Describe your feelings and emotions in detail (cf. Appendix for an example of expressive writing);

Write a text expressing what you felt after passing your baccalaureate (or another important exam). Describe your feelings and emotions in detail (cf. Appendix for an example of expressive writing).

\section{Corpus analyses using the EMOTAIX-Tropes software and dependent variables}

30 Once they had been typed up, the 49 corpora were analyzed using EMOTAIX-Tropes. These analyses were performed by two judges, who checked identifications (cf. EMOTAIX operating instructions) and compared their decisions. Inter-rater agreement was achieved for $90 \%$ of the corpora. For the remaining $10 \%$, we noted several types of disagreement, with some corpora giving rise to a single discordance, while others triggered four or five. The judges were asked to discuss these, and reach an agreement.

31 Once the corpus analyses were complete, several indicators were chosen (cf. EMOTAIX operating instructions). Results were subjected to the appropriate statistical calculations (Student's t-test and chi-square test) according to the nature of the dependent variables, in order to find out whether there were any significant differences between the two experimental conditions, i.e. passing or failing an exam. Linear regressions were then calculated in order to find out whether the anxiety scores 
could account for the number of terms that had been used. The aim was to show how emotional lexical items detected in written productions can be subjected to more or less fine-grained analyses (positive or negative valence of the entire set of emotional and affective items, distribution of this vocabulary across supracategories, supercategories and basic categories). It should be stressed that this article is too short to provide an exhaustive description of all the functionalities offered by Tropes for analyzing corpora, such as counting the various personal pronouns (Chung \& Pennebaker, 2007).

\section{Participants}

32 Forty-nine first-year psychology students volunteered to take part in this experiment, which they were told was entitled "Emotion and writing". The State-Trait Anxiety Inventory (STAI) developed by Spielberger et al. (1983) was used to measure participants' levels of anxiety (French-language version by Schweitzer \& Paulhan, 1990). For each item in the inventory, participants were asked to rate items on a 4point Likert scale according to "how you generally feel", such as "I feel pleasant" or "I take disappointments so keenly that I can't get them out of my mind". The higher the STAI trait score, the higher the participant's level of anxiety.

\section{Procedure}

33 The experimental material (in the form of folders) was laid out on tables in the classroom prior to the students' arrival. These folders contained the documents required to perform each step of the procedure. The experiment was undertaken in a group session and lasted one hour. On entering the classroom, each student randomly chose a seat at a table on which a folder was placed. This meant that the distribution of the students between the two sets of writing instructions ("Passing" or "Failing an exam") was entirely random.

34 The experiment took place as follows, at a pace imposed by one of the two experimenters in attendance:

35 (1) First of all, the participants answered the STAI trait questionnaire (approx. 3 minutes). (2) The participants then spent a further 3 minutes filling in the STAI state questionnaire (NB: the data yielded by this test are not reported in this article).

(3) Next, the students were allowed to look at the topic for their written production, after listening to the following instructions: "You are now going to write an essay. You will only stop writing when I tell you to. The test will last 20 minutes. Only write on one side of the sheets stapled together. Make sure you are as clear and accurate as possible. Try to give as much information as you can. You may begin now. Turn the stapled pages over and read the title (subject) of your essay carefully."

37 (4) Immediately after the writing phase, the 3-minute STAI state test was administered to the participants a second time (NB: the data yielded by this test are not reported in this article).

38 (5) Lastly, the participants were asked to fill in the writing apprehension questionnaire (WAT, Daly \& Miller, 1975; NB: the data yielded by this test are not reported in this article). 


\section{Results}

\section{Valence of the lexicon used for each writing topic}

Participants did not produce significantly more words in the "Pass" condition (240) than in the "Fail" one $(214 ; \mathrm{t}(47)=1.2, \mathrm{~ns})$. Compared with the total number of terms they used, they produced a significantly higher percentage of emotional items in the "Pass" condition (8.4\%) than they did in the "Fail" one $(6.6 \% ; t(47)=2.45, p<.02)$. The percentage of positive-valence items was significantly higher in the "Pass" condition (67.7\%) than in the "Fail" one (22.9\%; $t(47)=8.72, p<.0001$; NB: Percentages concerning the terms of positive and negative valence did not reach $100 \%$ because a small number of these terms were categorised as "SURPRISE, IMPASSIVENESS OR UNSPECIFIED EMOTIONS"). The percentages of negative-valence items were $34.2 \%$ for the "Pass" condition and 77.1\% for the "Fail" one. Lastly, in both conditions, the writers used more literal items than figurative ones ("Pass" condition: $88 \%$ vs. $13 \%$; $t(23)=20.12, p<.0001$; "Fail" condition: $85 \%$ vs. $17 \%$; $t(24)=13.73, p<.0001)$. There was no significant difference between the percentages of figurative items used by participants in the two conditions $(\mathrm{t}(47)=1.14, \mathrm{~ns})$.

\section{Nature of lexicon used according to the writing topic}

The mean numbers of emotional terms produced by participants in the two writing conditions were 19.67 terms for the "Pass" condition (SD = 9.28) and 13.96 for the "Fail" condition (SD = 6.63). Given the small number of emotional terms used, plus the fact that some emotional lexicon categories were only evoked by a small number of participants, we decided to use the chi-square goodness-of-fit test to assess the numbers of participants in each emotional category according to the "Pass" or "Fail" condition (NB: any participant who had produced at least one term belonging to a given category was counted for that category). Results are set out in Table 3. 
Table 3. Selected comparisons of the numbers of participants (Chi Square statistic $=X 2)$ who used different emotional lexicon categories (negative and positive, supracategories, supercategories, and basic categories) in each condition (passing or failing an exam).

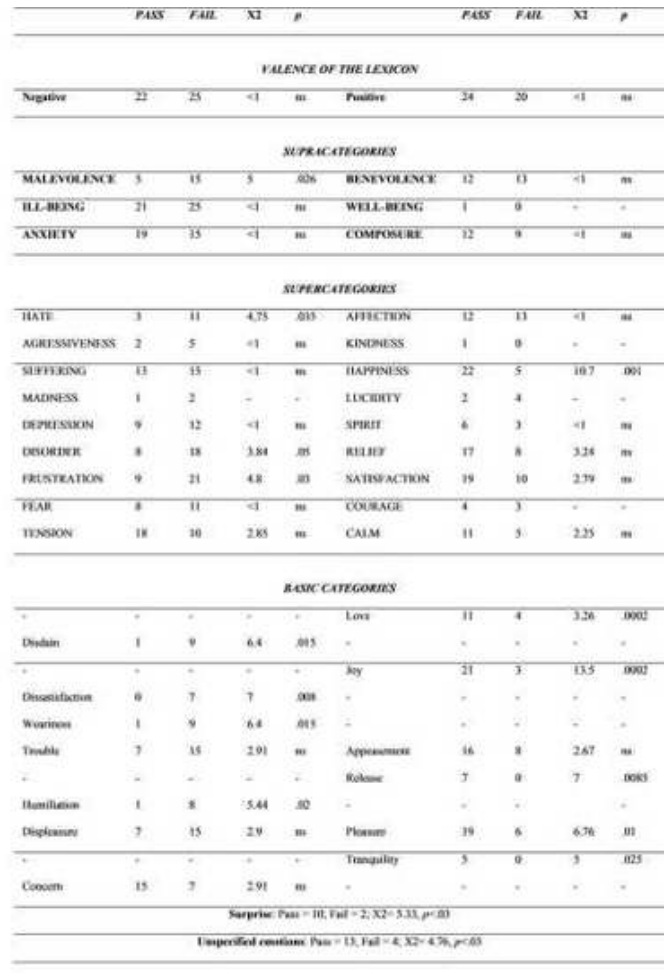

41 Whether they were describing the emotions they felt after passing or failing an exam, virtually all the participants used a combination of negative and positive lexical items. The number of participants using items from the various negative-valence categories was significantly higher for the Fail condition than for the Pass one (MALEVOLENCE, HATE, DISORDER, FRUSTRATION, Disdain, Dissatisfaction, Weariness, and Humiliation). Interestingly, the wordcounts for two categories (TENSION, Concern) were higher for the Pass condition than for the Fail one, albeit below the .05 significance level $(p=.13$ and $p=.09$ respectively). Significantly more participants used items from the different positive-valence categories in the Pass condition than in the Fail one (HAPPINESS, Love, Joy, Release, Pleasure, and Tranquility). Lastly, the number of participants who expressed SURPRISE was significantly greater in the Pass condition than in the Fail one. More participants expressed UNSPECIFIED EMOTIONS in the Pass condition than in the Fail one.

\section{Anxiety and choice of emotional lexicon according to writing topic}

To test whether the emotional lexical content (number of terms used) varied according to the participants' level of anxiety (STAI score), we calculated simple linear regressions. We only report regressions where the adjusted $\mathrm{R}^{2}$ explains more than $11 \%$ of variance (cf. Table 4), and only percentages above $25 \%$ are described in the text below. 
Table 4. Simple linear regressions for the content categories (positive- then negative-valence) in the two conditions (Pass then Fail)

\begin{tabular}{|c|c|c|c|c|c|c|}
\hline Conteat & $R^{2}(S)$ & B & $S B$ & B & $t$ & $p$ \\
\hline \multicolumn{7}{|c|}{ PASS CONDITION } \\
\hline Laugh & 128 & 023 & .012 & 94 & 2.09 & .05 \\
\hline $\begin{array}{c}\text { Nequative lexican } \\
\text { (complete) }\end{array}$ & 26.1 & 305 & .100 & s4 & 3.02 & 007 \\
\hline MALEVOLENCE & 163 & 208 & .121 & 44 & 234 & 03 \\
\hline HATE & 13.1 & .023 & .011 & 41 & 2.11 & .046 \\
\hline Irritation & 21.7 & .068 & 025 & 50 & 2.72 & ois \\
\hline II.L-BEIVG & 22,4 & 200 & .972 & 50 & 276 & 015 \\
\hline SUFFURING & 16.5 & .091 & .039 & 44 & 2.35 & .03 \\
\hline DEPRESSION & 25.8 & 108 & 036 & 30 & 3.00 & 607 \\
\hline Saderers & 20.1 & 081 & .031 & 48 & 2.60 & 02 \\
\hline Weariness & 32.3 & 029 & .008 & 59 & 3.46 & .003 \\
\hline FEAR & 17,1 & 973 & 030 & 45 & 230 & 026 \\
\hline Apprehensivan & 20.2 & .075 & .028 & 48 & 2.61 & ont \\
\hline \multicolumn{7}{|c|}{ FAIL CONDITION } \\
\hline HAPPINESS & 11.5 & -0.04 & .021 & -39 & 20 & 054 \\
\hline Jay & 14.8 & -030 & .013 & -42 & -2.27 & o35 \\
\hline SATISFACTION & 12.2 & -044 & 021 & .39 & .2 .08 & .05 \\
\hline HATE & 26.9 & 0152 & .016 & s4 & 3.13 & 005 \\
\hline Imitation & 12.9 & 015 & .007 & 40 & 2.13 & 045 \\
\hline
\end{tabular}

In the Pass condition, we observed just one significant result concerning the positivevalence lexicon: the more anxious they were, the more the participants evoked the "Laugh" emotion. Several other significant results were recorded in the Pass condition, insofar as the more anxious participants were, the more negative-valence items they used, accounting for $26.1 \%$ of variance. These items belonged to three different groups of categories: (1) MALEVOLENCE, HATE, Irritation; 2) ILL-BEING, SUFFERING, DEPRESSION (25.8\%), Sadness, Weariness (32.2\%); 3) FEAR, Apprehension).

44 Contrasting results were found for the Fail condition, concerning the positive-valence lexicon, as the more anxious they were, the fewer items they used reflecting HAPPINESS, Joy or SATISFACTION. Regarding the use of negative-valence items, the more anxious they were, the more items they used belonging to one particular group of categories (i.e. HATE (26.9\%) and Irritation).

\section{Discussion}

The aims of this article were twofold: 1 ) to introduce readers to a tool for analyzing the French emotional and affective lexicon (EMOTAIX, Piolat \& Bannour, 2009) and 2) to demonstrate how EMOTAIX can be used, in a study of the possible effect of students' anxiety on the way in which they express their feelings after passing or failing an exam.

In order to take advantage of the tool's ability to detect, classify and count lexical items contained in written productions, we devised three types of dependent variables. These provided us with a) an overview (e.g. the percentage of emotional items contained in the written productions), b) a summary of the emotional themes broached 
by the students (e.g. the number of students using each lexical category, such as WELLBEING, ILL-BEING) and lastly c) the number of terms used in the different categories of the EMOTAIX structure.

47 This strategy enabled us to make three observations. First of all, the pieces of expressive writing produced in the experimental conditions (Passing or Failing an exam) contained only a small proportion of emotional and affective items (less than $10 \%)$. Further studies are now needed to ascertain whether this observation holds for other expressive writing topics and to identify the conditions under which the use of emotional lexicon in expressive verbal productions may increase or decrease.

Our second observation concerns the nature of the emotional lexicon. The software's distribution of items across a large number of basic categories $((28 \times 2)+3)$ had a fragmenting effect (even if the range of lexical items used only covered a limited number of categories) especially when the actual number of terms used was low. Given that the words produced by the students did not all belong to the same categories, with one or two exceptions, instead of focusing on the mean number of terms per category, we looked at the numbers of students who had used at least one term in each of these categories. For this reason, we believe that the labels of the basic categories gave us a far better idea of what the students actually said than those of the nesting categories (super- and supracategories) which, in some cases, were rather disconcerting. For example, in the case of students who had expressed irritation, the system of nesting labels meant that this was qualified as "HATE" and, at an even higher level, as "ILLBEING". Thus, depending on the viewpoint adopted by researchers, it may be preferable to focus entirely on the results for the basic categories most often used by the students, as they are the ones with the most accurate labels. Then again, in other cases, too much information may be lost because too few participants have used certain basic categories and the statistical calculations therefore prove inadequate. In these circumstances, it may be advisable to use a less fine-grained analysis, using a higher level of categorization in order to group together populations of participants with scattered lexical choices. When doing so, the super- and supracategory labels must be handled with care, in order to accurately summarize the content of the verbal productions.

49 Our third and final comment concerns the best way of treating the number of terms used per category as a dependent variable. For those categories where the lexicon has been used by a large number of participants, this is a relevant variable, as it reflects the increase with which participants have explicitly expressed an affective state. This proved to be a relevant variable for assessing whether the students' level of anxiety could explain the nature of the affective states they expressed.

50 Regarding the second aim of this article, the study we chose as an illustration yielded three observations. First of all, the students responded to the instructions by evoking the relevant emotional content (Success or Failure). Their choice of emotional lexicon mostly reflected positive emotions when they recounted their feelings after passing the exam and negative emotions when they described a failure. More interestingly, the affective information was not restricted to the expression of pleasant affect for the Success condition, just as it was not limited to the expression of negative affect for the Failure condition. These feelings were justified in the narrative by a change of state, such as "Being really apprehensive about the exam results, then experiencing the joy of success and feeling appeased" or quite the opposite, "Making positive projects after a successful exam then, with the news of my failure, discovering suffering, accompanied 
by troubled feelings and irritation". The two imposed expressive writing conditions thus gave rise to texts containing both positive- and negative-valence items. The only difference was that is the Success condition, more students mentioned the feeling of surprise.

51 These results are line with those reported by Pennebaker, Mehl and Niederhoffer (2003), who regard language use as reflecting what we are, our personality and the way we react to situations in everyday life. The way the students framed their narratives depended on their anxiety levels. When describing their feelings after passing an exam, the more anxious the students were, the more negative-valence items they included. They gave vent more freely to their irritation, sadness, weariness and apprehension, only to laugh about it when they learned that they had passed. When describing how they failed an exam, however, they mentioned fewer positive elements, thus reducing the contrast in any "positive-affective- state-to-negative-one"-type narrative. Here, once again, more of them used lexical terms belonging to the "HATE" supercategory.

52 Given that the students' states of anxiety were only characterized in a general fashion (Spielberger trait anxiety inventory, 1972), further studies are now needed. Insofar as the students expressed their feelings in writing, it would be interesting to find out whether anxiety more specifically linked to the act of writing also affects the way they recount their feelings in situations of exam success or failure.Writing is an extremely effortful cognitive activity (Kellogg, 1996) and its very performance can trigger anxiety, as students may develop different self-efficacy beliefs during the lengthy process of acquiring writing skills. Daly (1985) and Onwuegbuzie (1997) both highlighted the effects of writing/composition anxiety/apprehension on writing performances and writing avoidance. It would be interesting to use EMOTAIX-Tropes to demonstrate that the evocation of emotional feelings can also be modulated by this more specific form of anxiety.

\section{BIBLIOGRAPHY}

Averill, J. R. (1980). On the paucity of positive emotions. In K. R. Blankstein, P. Pliner \& J. Polivy (Eds.) Advances in the study of communication and affect:Assessment and modification of emotional behavior, Volume 6 (pp. 7-45). New York: Plenum.

Bannour, R., Piolat, A., \& Gombert, A. (2008). Quand des lycéens et des étudiants rendent compte de leurs émotions... Effets de leur niveau d'appréhension et du thème rédactionnel [Effect of the level of apprehension and of the written topic among 12th grade students]. In F. Grossmann \& S. Plane (Eds.). Les apprentissages lexicaux: Lexique et production verbale (pp. 233-252). Villeneuve d'Ascq: Presses Universitaires du Septentrion.

Bermond, B., Vorst, H. C., Vingerhoets, A. J., \& Gerritsen, W. (1999). The Amsterdam Alexithymia Scale: Its psychometric values and correlations with other personality traits. Psychotherapy and Psychosomatics, 68, 241-251. 
Chung, C. K., \& Pennebaker, J. W. (2007). The psychological function of function words. In K. Fiedler (Ed.), Social communication: Frontiers of social psychology (pp 343-359). New York: Psychology Press.

Cowie, R., \& Cornelius, R. R (2003). Describing the emotional states that are expressed in speech. Speech Communication, 40, 5-32.

Daly, J. A., \& Miller, M. D. (1975). The empirical development of an instrument to measure writing apprehension. Research in the Teaching of English, 9, 250-256.

Daly, J. A. (1985). Writing apprehension. In M. Rose (Ed.), When a writer can't write: Studies in writer's block and other composing process problems (pp. 43-82). New York, NY: Guilford.

Feldman Barrett, L., \& Russell, J. A. (1999). The structure of current affect: Controversies and emerging consensus. Current Directions in Psychological Science, 8, 1, 10-14.

Fontaine, J. R., Scherer, K. R., Oiesch, E. B., \& Ellsworth, P. (2007). The world of emotion is not two-dimensional. Psychological Science, 13(2), 1050-1057.

Frijda, N., Markam, S., Sato, K., \& Wiers, R. (1995). Emotions and emotion words. In J. A. Russell, J. M. Fernandez-Dols, A. S. R. Manstead, \& J. C. Wellenkamp (Eds.), Everyday conceptions of emotion: An introduction to the psychology, anthropology and linguistics of emotion (pp. 121-143). Dordrecht (Netherlands) \& Boston: Kluwer Academia.

Galati, D., \& Sini, B. (1998). Echelonnement multidimensionnel du lexique français des émotions. Une comparaison entre trois procédés d'analyse. Les Cahiers Internationaux de Psychologie Sociale, 37, 76-99.

Goldman, S. R., Graesser, A. C., \& Broek Van Den, P. (1999) (Eds.). Narrative comprehension, causality, and coherence: Essays in honor of Tom Trabasso. Hillsdale, NJ: Lawrence Erlbaum Associates.

Kellogg, R. T. (1996). A model of working memory in writing. In M. C. Levy \& S. E. Ransdell (Eds.). The science of writing. Theories, methods, individual differences and applications (pp. 57-71). Hillsdale, NJ: Laurence Erlbaum Associates.

Kring, A. M., Smith, D. A., \& Neale, J. M. (1994). Individual differences in dispositional expressiveness: Development and validation of the Emotional Expressivity Scale. Journal of Personality and Social Psychology, 66, 934-949.

Larsen, R. J., \& Diener, E. (1987). Affect intensity as an individual difference characteristic: A review. Journal of Research in Personality, 21, 1-39.

Lindquist, K., Barrett, L. F., Bliss-Moreau, E., \& Russell, J. A. (2006). Language and the perception of emotion. Emotion, 6, 125-138.

Loas, G., Otmani, O., Verrier, A., Fremaux, D., \& Marchand, M. P. (1996). Factor analysis of the French version of the 20-item Alexithymia Scale (TAS -20). Psychopathology, 29, 139-144.

McCroskey, J. C., Beatty, M. J., Kearney, P., \& Plax. T. G. (1985). The content validity of the PRCA-24 as a measure of communication apprehension across communication contexts. Communication Quarterly, 33, 165-173.

Niedenthal, P. M., Auxiette, C., Nugier, A., Dalle, N., Bonin, P., \& Fayol, M. (2004). A prototype analysis of the French category "émotion". Cognition and Emotion, 18 (3), 289-312.

Ortony, A., \& Turner, T. J. (1990). What's basic about basic emotions? Psychological Review, 97, 315-331. 
Onwuegbuzie, A. (1997) Writing a research proposal: The role of library anxiety, statistics anxiety, and composition anxiety. Library \& Information Science Research, 19(1), 5-33.

Pajares, F. (2002). Self-efficacy beliefs in academic contexts: An outline. [Retrieved October 15, 2008, from http://des.emory.edu/mfp/efftalk.html].

Pennebaker, J. W., Chung, C. K., Ireland, M., Gonzales, A., \& Booth, R. J. (2007). The development and psychometric properties of LIWC2007. Austin, TX: LIWC.net

Pennebaker, J. W., Francis, M. E., \& Booth, R. J. (2001). Linguistic Inquiry and Word Count: LIWC 2001. Mahwah, NJ: LawrenceErlbaum.

Pennebaker, J. W., Mehl, M. R., \& Niederhoffer, K. (2003). Psychological aspects of natural language use: Our words, our selves. Annual Review of Psychology, 54, 547-577.

Piolat, A., \& Bannour, R. (in press). EMOTAIX: Un scénario de Tropes pour l'identification automatisée du lexique émotionnel et affectif [EMOTAIX: A Scenario using Tropes for automatized identification of emotional and affective lexicon]. L'Année Psychologique.

Plutchik, R. (2005). Emotions and life. Perspectives from psychology, biology, and evolution. Washington, DC: American Psychological Association.

Ramirez-Esparza, N., Pennebaker, J. W., Garcia, F. A., \& Suria, R. (2007). La psychología del uso de las palabras: Un programa de comutadora que analiza textos en Español (The psychology of word use: A computer program that analyzes texts in Spanish). RevistaMexicana de Psicología, 24, 85-99.

Russell, J. A. (2003). Core affect and the psychological construction of emotion. Psychological Review, 110, 1, 145-172.

Scherer, K. R. (2001). Appraisal considered as a process of multi-level sequential checking. In K. R., Scherer, A., Schorr, \& T., Johnstone (Eds.), Appraisal Processes in Emotion: Theory, Methods, Research (pp. 92-120). New York and Oxford: Oxford University Press.

Scherer, K. R. (2005). What are emotions? And how can they be measured? Social Science Information, 44(4), 693-727.

Shaver, P., Schwartz, J., Kirson, D., \& O'Connor, C. (1987). Emotion knowledge: Further exploration of prototype approach. Journal of Personality and Social Psychology, 52, 1061-1086.

Sifneos, P. E. (1988). Alexithymia and its relationship to hemispheric specialization, affect, and creativity. Psychiatry Clinics of North America, 11, 287-292.

Smyth, J., \& Pennebaker, J. W. (2008). Exploring the boundary conditions of expressive writing: In search of the right recipe. British Journal of Health Psychology, 13, 1-7.

Spielberger, C. D. (1972). Anxiety as an emotional state. In C. D. Spielberger (Ed.), Anxiety: Current trends in theory and research, Vol. 1 (pp. 24-49). New York: Academic Press.

Spielberger, C. D., Gorsuch, R. L., Lushene, R., Vagg, P. R., \& Jacobs, G. A. (1993). Manuel de l'inventaire d'anxiété état-trait forme Y (STAI-Y) [STAI form Y manual] (M. Bruchon-Schweitzer \& I. Paulhan, transl. into French). Paris: Editions du Centre de Psychologie Appliquée.

Storm, C., \& Storm, T. (1987). A taxonomic study of the vocabulary of emotions. Journal of Personality \& Social Psychology, 53, 805-816.

Tropes. Le logiciel d'analyse de textes [Text analysis software], retrieved February 5, 2009, from http://www.acetic.fr/tropes.htm. 
Watson, D., Clark, L. A., \& Tellegen, A. (1988). Development and validation of brief measures of positive and negative affect: The PANAS scales. Journal of Personality and Social Psychology, 54, 1063-1070.

Wells, A., \& Davies, M. I. (1994). The thought control questionnaire: A measure of individual differences in the control of unwanted thoughts. Behaviour Research and Therapy, 32, 871-878.

Wolf, M., Horn, A., Mehl, M., Haug, S., Pennebaker, J. W., \& Kordy, H. (2008). Computergestützte quantitative Textanalyse: Äquivalenz und Robustheit der deutschen Version des Linguistic Inquiry and Word Count [Computer-aided quantitative text analysis: Equivalence and robustness of the German adaptation of the Linguistic Inquiry and Word Count]. Diagnostica, 54, 85-98.

\section{APPENDIXES}

\section{Example of expressive writing: Exam failure condition}

When I failed this exam, I felt quite destabilized. Doubt soon started to take hold of me. I could no longer be certain about anything. The first thought that came into my head was that this situation was impossible to accept - not because I'm someone with a lot of self-confidence, but because I knew that I would find it hard to get over it.

After this news and this feeling of failure, I tried to put it into perspective, by comparing it with more serious situations. But this state didn't last for very long.

I was once more submerged by feelings of inability and failure, of staring into an abyss, and of finding myself in a dead end.

As soon as I'm confronted with failure, I start having doubts about everything, I totally reassess myself. I go back over all the failures I've had in my life. I realize that this is a difficult type of situation. My next reaction is not to dwell on the matter, not to talk about it, as it's often too painful.

I then start to feel rage. An urge to destroy everything, but above all to take it out on something or somebody. To vent my anger and release all my pent-up stress and emotion.

I think it must be this feeling of rage that enables me to persevere. To prove to other people and above all to myself that I'm capable of succeeding.

\section{Example of expressive writing: Exam success condition}

Given that the year leading up to the baccalaureate had not been particularly studious, I was extremely uncertain about the results.

In fact, I thought I probably wouldn't pass. To tell the truth, that's what I expected and I was ready to repeat a year at school. That's why I was weighing the pros and cons of passing or failing on my way to school. Even so, I was very tense just before I left to get the results, although at the start of the day I'd felt calmer, I didn't really believe I'd passed and I didn't want to go and see the results, but I knew I had to.

As I started to put things into perspective on my way there, I calmed down a little. Even if I hadn't passed (and there would be nothing surprising about that), it didn't matter that much. In any event, when I reached the school gates, a friend of mine told me I'd passed, like her and another friend, and that made me feel great. The advantages of not 
having to spend another year at school suddenly overshadowed all the disadvantages. I felt proud of myself, because despite all expectations (mine as well as those of the people around me), I'd succeeded. If I was pleased, it was more because I'd got my "revenge" on those who hadn't had shown any confidence in me than because I'd got that diploma. My strongest feeling that day, I think, was one of pride.

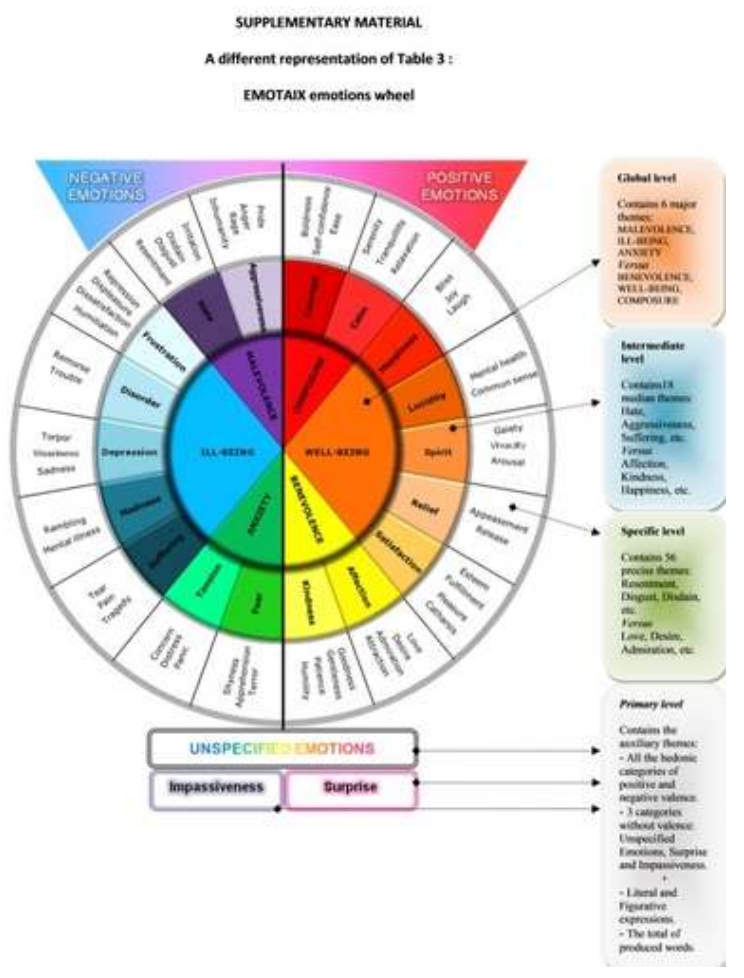

\section{ABSTRACTS}

This article comes in two sections. The first one provides an introduction to the EMOTAIX-Tropes text analysis software, describing the method that was used to create the collection of terms (4,921 words belonging to the emotional and affective lexicon), the three-tiered thematic organization of this lexicon on either side of a hedonic axis, and the software operating instructions. The second section explains how EMOTAIX can be applied in an experiment. A study of the impact of students' anxiety on the way they described their feelings (expressive writing) after passing or failing an exam yielded some entirely new results. Students used both positiveand negative-valence items in both situations. Particularly anxious subjects, however, were found to maximize emotional items conveying ill-being when describing their success and to minimize ones with a positive valence when relating a failure.

Cet article contient deux parties. Dans la première, a text analyse software (EMOTAIX-Torpes) est décrite: modalités de rassemblement de la collection de termes, soit 4921 mots de lexique émotionnel et affectif ; structuration thématique de ce lexique en trois niveaux autour d'un axe hédonique; mode d'emploi. Dans la seconde partie, la façon dont EMOTAIX peut être expérimentalement utilisé est présentée. La recherche sur la façon dont l'anxiété des étudiants modulent leur façon d'expliciter leurs ressentis (expressive writing) à l'occasion d'un échec ou d'une réussite à un examen apportent des résultats inédits. Dans les deux situations les étudiants emploient du lexique de valence positive et négative. Mais, les étudiants les plus anxieux 
maximisent le lexique émotionnel traduisant un mal-être quand ils exposent une réussite et minimisent le lexique émotionnel de valence positive lorsqu'ils rendent compte d'un échec.

INDEX

Keywords: Text analysis software, affective lexicon, emotional lexicon, anxiety, expressive writing

\section{AUTHORS}

\section{ANNIE PIOLAT}

Centre de Recherche en Psychologie de la Connaissance, du Langage et de l'Émotion - (EA 3273) Aix-Marseille Université, 29 avenue Robert Schuman, F-13621 Aix-en-Provence Cedex 1 Annie.Piolat@univ-provence.fr

\section{RACHID BANNOUR}

Centre de Recherche en Psychologie de la Connaissance, du Langage et de l'Émotion - (EA 3273) Aix-Marseille Université, 29 avenue Robert Schuman, F-13621 Aix-en-Provence Cedex 1

Rachid.Bannour@univ-provence.fr 